Klinik Araştırma / Clinical Research

\title{
Bezoarların medikal tedavisinde ananas suyu: 4 hasta ile klinik deneyimimiz
}

\author{
Ananas juice for medical treatment of bezoars: Clinical experience with 4 patients \\ İlhan Karabıçak*, Savaş Yürüker, Tuğrul Kesicioğlu, Hamza Çınar, Cafer Polat, Necati Özen \\ Ondokuz Mayıs Üniversitesi, Tıp Fakültesi, Genel Cerrahi Anabilim Dall, Samsun
}

\begin{tabular}{|c|c|}
\hline \multicolumn{2}{|c|}{ MAKALE BİLGİLERİ } \\
\hline \multicolumn{2}{|c|}{ Makale geçmişi } \\
\hline Geliş & 08 / 04 / 2011 \\
\hline Kabul & 09 / 04 / 2011 \\
\hline
\end{tabular}

\author{
* Yazışma Adresi: \\ İlhan Karabıçak \\ Ondokuz Mayıs Üniversitesi, \\ Tıp Fakültesi, Genel Cerrahi A.D. \\ Kurupelit, Samsun \\ e-posta: ikarabicak@omu.edu.tr
}

\author{
Anahtar Kelimeler: \\ Ananas suyu \\ Akut barsak tıkanması \\ Medikal tedavi \\ Karın ağrısı \\ Bezoar \\ Cerrahi tedavi
}

\section{Keywords:}

Pineapple juice

Acute intestinal obstruction

Medical treatment

Abdominal pain

Bezoar

Surgery

\section{ÖZET}

Bezoarlar gastointestinal sistemde bulunan yabancı cisimlerin oluşturduğu sert kitlelerdir. Midede bulunan bezoarlar medikal olarak tedavi edilebilir. Bezoara bağlı gelișen akut barsak tıkanmasının tek tedavisi cerrahidir. Bu çalışmada akut barsak tıkanmasına neden olan bezoarların medikal tedavileri irdelenmektedir. Son 5 yıl içinde hastanemize bezoarlara bağlı akut barsak tıkanması ile 22 hasta yatırıldı. Onsekiz hasta ameliyat edildi. Medikal tedaviyi tolere edebilecek olan 4 hastaya ananas suyu tedavisi uygulandi. Medikal tedavi uyguladığımız 4 hastada ortalama 3 gün boyunca devam eden bulantı, kusma ve distansiyon şikayetleri mevcuttu. Ayakta direk batın grafilerinde hava-sıvı seviyeleri saptandı. Tüm hastalarda bilgisayarlı tomografide ince barsakta kısmi tıkanmaya yol açmış bezoar ile uyumlu kitle saptand. Tüm hastalar medikal tedaviye cevap verdi. Akut barsak tıkanmasına sebep olan ve genel durumu medikal tedaviyi tolere edebilecek olan hastalarda ananas suyu ile medikal tedaviler denenebilir. J. Exp. Clin. Med., 2011; 28:55-58

\begin{abstract}
Bezoars are concretions or hard masses of foreign matter that are found in the gastrointestinal tract. Gastric bezoars can be treated medically. Surgery is the only treatment option for acute intestinal obstruction secondary to bezoars. In this report, we share our experience of medical treatment with pine apple juice for acute intestinal obstruction secondary to bezoars. We hospitalized 22 patients for acute intestinal obstruction secondary to bezoars. Eighteen of them underwent surgical treatment. Four patients who were able to tolerate medical treatment, were treated medically with pine apple juice. All patients were admitted with complaints of nausea, vomiting and distention for a period of 3 days. Plain abdominal graphy showed air-fluid levels and CT scan showed intestinal obstruction secondary to bezoars. All patients responded to medical treatment. Patients with intestinal obstruction secondary to bezoars can be treated medically with pine apple juice if they are able to tolerate medical treatment.
\end{abstract}

J. Exp. Clin. Med., 2011; 28:55-58

(C) 2011 OMU All rights reserved

\section{Giriş}

Bezoarlar; gastrointestinal sistemde görülen ve sıklıkla midede oluşan taşlaşmış gıda veya yabancı cisimlerdir. Genellikle mide ameliyatı geçirmiş veya midenin peristaltik ve işlevsel bozukluğu olan kişilerde görülür. İntestinal tıkanma bezoarların en sik görülen komplikasyonudur (Cifuentes ve ark,. 1992; Erzurumlu ve ark., 2005; Latic ve ark., 2010). Tedavisi sıklıkla cerrahi gerektirmekle birlikte, eritme amaçlı medikal uygulamalar da bildirilmiştir (Staten ve ark., 1975; Feffer ve ark., 1976).

Kliniğimizde, bezoar kaynaklı barsak tıkanması nedeniyle yatırdığımız hastalar cerrahi, endoskopik ve medikal olarak tedavi edilmektedir. Bezoara bağlı akut barsak tıkanması gelişen ve ananas suyu ile tedavi ettiğimiz 4 olgumuzu literatür 1şığında kısa bilgi vererek sunmayı amaçladık.

\section{Yöntem ve Gereçler}

Ocak 2005- Şubat 2011 yılları arasında, Ondokuz Mayıs Üniversitesi Tıp Fakültesi Genel Cerrahi servisine bezoara bağlı akut barsak tıkanması nedeniyle yatırılan 22 hastanın dosyaları geriye dönük olarak incelendi.

\section{Sonuçlar}

Bezoara bağlı akut barsak tıkanması nedeniyle yatırılan 22 hastanın 18'i cerrahi girişimle ve 4'ü ise ananas suyu ile medikal olarak tedavi edildi. Ananas suyu ile tedavi ettiği- 
miz 4 hastanın üçünde bezoar jejunumda, 1 hastada da ileumda akut tıkanmaya neden olmuştu. Bezoar oluşumu için risk faktörleri araştırıldığında 2 hastanın mide ülseri nedeniyle ameliyat olduğu, bir hastanın Trabzon hurması yediği, bir hastanın da mide ağrısı nedeniyle sürekli ilaç kullanan ve asitli içecekleri hiç içmeyen hasta olduğu saptandı. Hastaların demografik özellikleri tablo 1'de gösterilmiştir.

\section{Tartışma}

Bezoar oluşumunda anatomik, diyet ve sindirim sistemi ile ilgili bir çok predispozan faktörden bahsedilmektedir. Bu faktörlerden, midede motilite bozukluğu oluşturan vagotomi ve sonrasında gelişen midede hızlı boşalma, asit salgısının azalması ve daha yoğun mide içeriğinin oluşması üzerinde durulmaktadır. İlave olarak gastrektomi ya da gastroenterostomi mevcutsa daha geniş hacimde solid materyallerin ince bağırsağa inmesinin riski daha da arttıracağı belirtilmektedir. Gastrointesinal yerleşimli bezoarlar hiçbir semptom vermeden sessiz kalabileceği gibi, ciddi akut batın tablosu kliniğine kadar varan sonuçlara neden olabilmektedir (Zissin ve ark., 2004; Bedioui ve ark., 2008).

İntestinal tıkanmaya yol açmış bezoarlar çeşitli cerrahi teknikler ile başarılı şekilde tedavi edilebilmektedir. Mideye yerleşmiş bezoarlar endoskopik yöntemlerle, barsaklarda t1kanmaya yol açan bezoarlar ise konvansiyonel veya laparoskopik cerrahi ile enterotomi yapılarak veya sağılma yöntemi ile tedavi edilebilmektedir (Cifuentes ve ark., 1992; Erzurumlu ve ark., 2005; Latic ve ark., 2010).

Mideye yerleşmiş ve barsak tıkanmasına yol açmamış bezoarların medikal olarak başarılı bir şekilde tedavi edildiği bildirilmektedir. Medikal tedavi için şimdiye kadar farklı birçok madde kullanılmıştır. Medikal tedavinin amacı bezoarları küçük parçalara ayırıp, doğal yolla vücut dışına atılmasını sağlamaktır. Medikal tedavi 3 şekilde etki etmektedir: 1) enzimatik (mukolitik, proteolitik, selülolitik), 2) mekanik (endoskopik lavaj) ve 3) diğerleri (takip, metoklopramid tedavisi veya sıvı diet) (Dwivedi ve ark., 2001). Vaka sayılarının kısıtlı olmasından dolayı uygulanacak medikal tedavinin içeriği, süresi ve dozu hakkında fikir birliği bulunmamaktadir.

Medikal tedavi için ananas suyu, Coca-Cola, N-asetil sistein, serum fizyolojik, papain içeren et yumuşatıcı soslar, papain-bikarbonat solüsyonu, selüloz, selülloz ve papain, 0,1 $\mathrm{N}$ hidroklorik asit, sodyum bikarbonat, pankrealipaz, pankreatin, \%1-2 çinko klorid, pankrealipaz ve askorbik asit, selüloz, sistein ve metoklopramid kombinasyonu, hazır enteral beslenme solüsyonları, gastrografin gibi farklı maddeler başarılı bir şekilde kullanılmıştır (Dugan ve ark., 1972; Meyer ve ark., 1973; Staten ve ark., 1975; Feffer ve ark., 1976; Rumley ve ark., 1983; Wyatt ve ark., 1993; Robles ve ark., 1994; Dwivedi ve ark., 2001; Gaya ve ark.,2002; Ladas ve ark., 2002; Ha ve ark., 2007; Sanei Taheri ve ark., 2008; Heinz-Erian ve ark., 2010). Medikal tedavi sırasında bezoarların parçalanmasına bağlı olarak akut barsak tıkanması gelişen vakalar bildirilmiştir. Bu nedenle medikal tedavi uygulanan hastalarda erken ve geç dönemde barsak tıkanması gelişebileceği akılda tutulmalı, hastalar düzenli takip edilmeli ve bu konuda hastanın bilgilendirilmesi gerektiği vurgulanmaktadır (Rumley ve ark., 1983; Nomura ve ark., 1997; Gaya ve ark., 2002; Ha ve ark., 2007).

Mide yerleşimli büyük bezoarların medikal tedavi öncesi endoskopik olarak parçalanması durumunda medikal tedavinin başarısının artabileceği belirtilmektedir. Gaya ve ark. endoskopi ile bezoarı parçaladıktan sonra L-sistein $(20 \mathrm{mg}$, günde $3 \mathrm{kez}$ ), selüloz (100 mg, günde $3 \mathrm{kez}$ ) ve metoklopramid (5 mg, günde $3 \mathrm{kez}$ ) kombinasyonunu 1 ay boyunca kullanarak hastalarını başarılı bir şekilde tedavi ettiklerini bildirdiler (Gaya ve ark., 2002).

Taheri ve ark., midede bezoar saptadıkları 2 hastaya nazogastrik sondadan 24 saatte 4 litre serum fizyolojik vererek ve 24 saatin sonunda hastaların karın ağrısının azaldığı, distansiyonun kaybolduğunu saptamışlar (Sanei Taheri ve ark., 2008).

Erian ve ark. yaşları 15 ile 19 ay arasında değişen 3 çocuk hastayı nazogastrik tüpten 6 saatte bir günde $5-8 \mathrm{kez} 10 \mathrm{mg} /$ $\mathrm{kg} \mathrm{N}$-asetil sistein vererek tedavi etmişler (Heinz-Erian ve ark., 2010).

Tablo 1: Hastaların demografik özellikleri, risk faktörleri, bezoarların yerleşim yeri ve sayısı.

\begin{tabular}{ccclcc}
\hline No & Cins & Yaş & \multicolumn{1}{c}{ Risk Faktörleri } & $\begin{array}{c}\text { Bezoarın } \\
\text { Yerleşim Yeri }\end{array}$ & $\begin{array}{c}\text { Bezoar } \\
\text { Sayısı }\end{array}$ \\
\hline 1 & K & 18 & $\begin{array}{l}\text { Asitli içecek kullanmama, } \\
\text { Sürekli H2 reseptör blokeri } \\
\text { kullanma }\end{array}$ & Mide, ileum & 2 \\
& & & & & \\
2 & K & 53 & $\begin{array}{l}\text { Sürekli tüketilen Trabzon } \\
\text { hurması }\end{array}$ & Jejunum & 1 \\
3 & E & 53 & $\begin{array}{l}\text { Geçirilmiş mide operasyonu } \\
\text { (Gastroenterostomi) }\end{array}$ & Jejunum & 1 \\
4 & K & 54 & $\begin{array}{l}\text { Geçirilmiş mide operasyonu } \\
\text { (Gastroenterostomi) }\end{array}$ & Jejunum & 1 \\
\hline
\end{tabular}

Wyatt ve ark., 4 gün boyunca enteral beslenme solüsyonu ile besledikleri hastada midedeki bezoarın kaybolduğunu saptamışlar (Wyatt ve ark., 1993). Papaya meyvesinde bulunan ve genellikle et yumuşatıcı soslarda kullanılan, proteinleri parçalayan bir enzim olan papain ile bezoarın medikal olarak tedavi edildiği vakalar bildirilmiştir (Dugan ve ark., 1972; Meyer ve ark.,1973; Staten ve ark., 1975). Ladas ve ark., endoskopik olarak bezoarın parçalanamadığ 15 hastayı 3 litre Coca-Cola'yı nazogastrik sondadan 12 saatte vererek tek seansta tedavi etmiş ve bu tedaviye bağlı bir komplikasyonun gelişmediğini bildirmiştir (Ladas ve ark., 2002). Ladas'ın bu ilk bildirisinden sonra Coca-Cola ile tedavi edilen başka vakalar da bildirilmiştir (Meseguer ve ark., 2008).

Bezoarların medikal tedavisinde ananas suyu ilk olarak Feffer ve ark., tarafından kullanmıştır (Feffer ve ark., 1976). Feffer'den sonra ananas suyunun kullanıldığı başka vakalar da bildirilmiştir (Walker ve ark., 1993). Ülkemizde de mide yerleşimli bezoarların medikal tedavisinde ananas suyu tercih edilen vakalar bildirilmiştir (Türkmenoğlu ve ark., 2008).

Literatür verileri incelendiğinde bezoarların ananas suyu veya başka maddelerle medikal tedavisi özellikle mide yerleşimli bezoarlar için tercih edildiği görülmektedir. Bizim sunmuş olduğumuz 4 hasta mekanik ince barsak tıkanması nedeniyle yatırılıp takibe alınmıştı. Dört hasta da ortalama 3 gündür var olan karın ağrısı, bulantı ve kusma şikayeti ile acile başvurdu. Fizik muayenede hastaların tümünde karında 
distansiyon mevcuttu. Belirgin rebound, hassasiyet ve defans gibi peritonit bulguları yoktu. Tüm hastaların ayakta direkt batın grafisinde ince barsak hava-sıvı seviyeleri mevcuttu (Şek. 1).

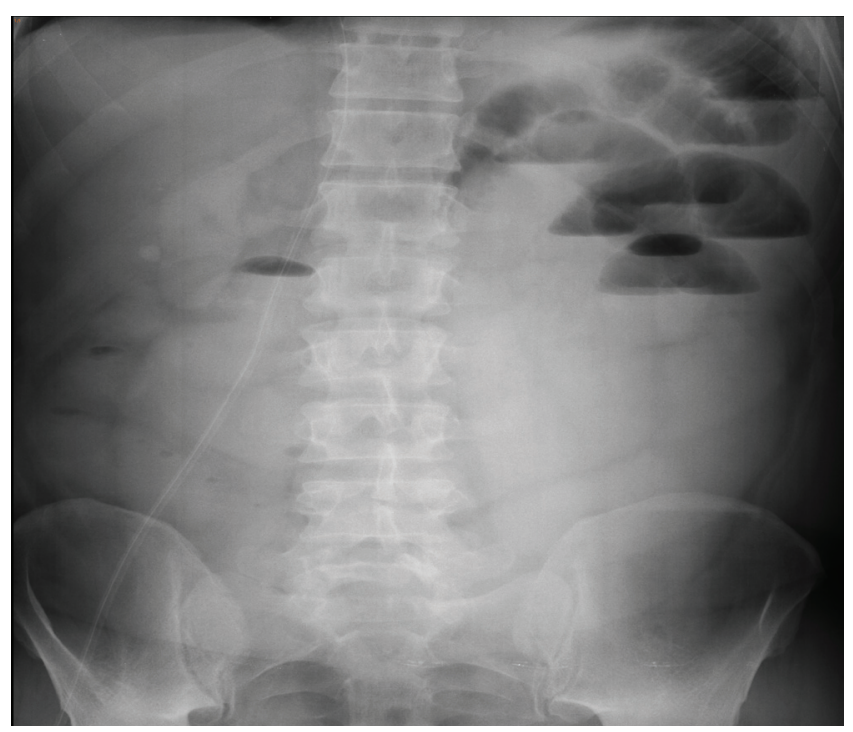

Şek. 1. İnce barsaklarda hava-sıvı seviyeleri görülmektedir.

Hastaların laboratuar incelemelerinde hafif lökositoz d1şında bir patoloji saptanmadı. Hastalara nazogastrik sonda ile dekompresyon uygulanarak medikal tedavi ile takibe alındi. İki hastada mide ülserine bağlı ameliyat hikayesi olduğundan görüntüleme öncesinde brid ileus düşünüldü. Tüm hastalara Bilgisayarlı Tomografi (BT) çekildi. Çekilen BT'ler sonucunda 3 hastada jejunumda, 1 hastada ileumda tıkanmaya yol açmış bezoar ile uyumlu kitle saptandı (Şek. 2).

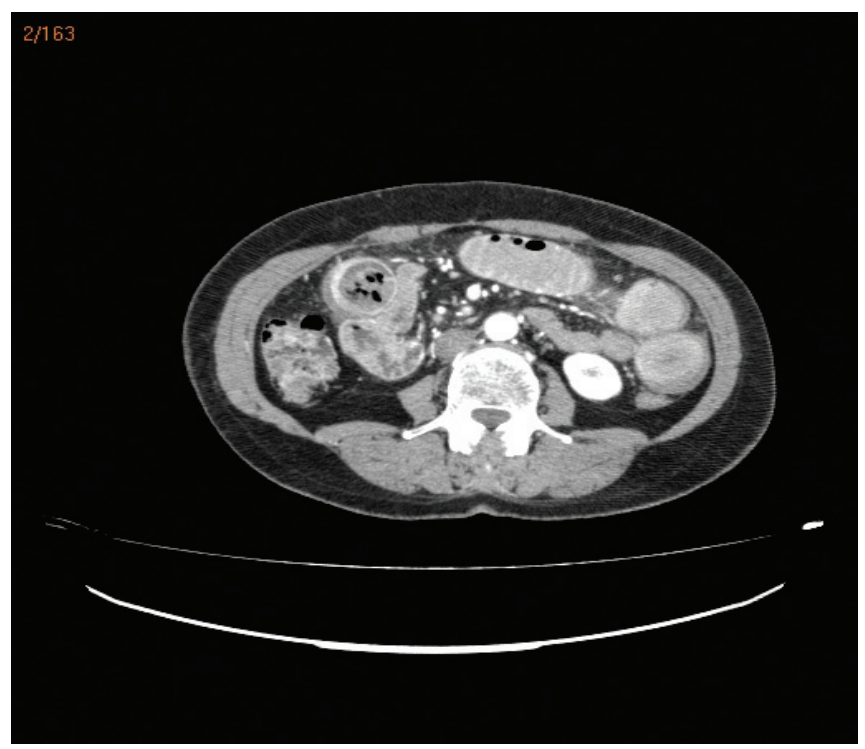

Şek. 2. İleumda tıkanmaya yol açmış bezoar ile uyumlu kitle.
Hastaların genel durumu medikal tedaviyi tolere edebilecek düzeyde olması ve klinik muayenelerinde acil operasyon gerektirecek durum olmadığı düşünüldüğünden medikal tedaviye karar verildi. Nazogastrik sondadan günde 3 kez 300 cc ananas suyu verildi. Ananas suyu verildikten sonra nazogastrik sonda 45 dakika klampe edildi. Bu tedavi ortalama 3 gün uygulandı. Ananas suyu ile tedavi süresince hastalar, fizik muayene ve laboratuar değerleri ile sürekli izleme alındı. Akut batın bulgularının gelişmemesi, ateş ve lokosit değerlerinde artış olmaması ve tolerasyonun iyi olmasından dolayı medikal tedaviye devam edildi. Takipleri sonucu distansiyonu kaybolan, barsak hareketleri normale dönen ve gaz-gaita çıkaran hastaların nazogastrik sondaları çekildi (Şek. 3).

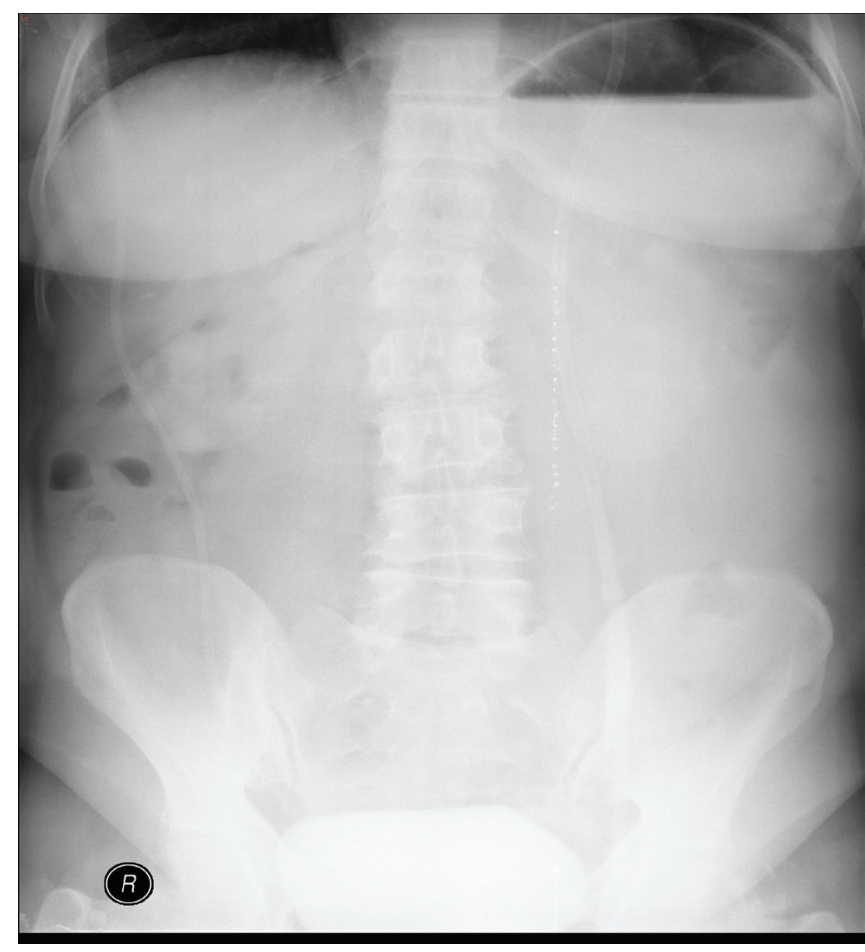

Şek. 3. Takipleri sonucunda distansiyonu kaybolan barsak hareketleri normale dönen ve gaz-gaita çıkaran hastanın ayakta direkt batın grafisi.

Hastanede ortalama 3 gün daha ananas suyu uygulamas1na devam edildi. Klinik olarak tamamen düzelen hastalar, ara sıra ananas suyu içmeleri tavsiye edilerek kontrole gelmek üzere şifa ile taburcu edildi.

Sonuç olarak; mide ve barsak yerleşimli bezoarlarda sıkı ve dikkatli bir gözlem altında uygun vakalarda medikal tedavi olarak ananas suyu denenebilir. Genellikle cerrahi girişim hikayesi ve tekrarlayabilen atakları olan bu hastalar cerrahi girişimin oluşturacağ 1 ilave riskten korunmuş olacaktır. Medikal tedaviye cevap vermeyen hastalarda bezoar dişı ileus oluşturan diğer patolojilerin olabileceği ihtimali unutulmamalidir.

\section{KAYNAKLAR}

Bedioui, H., Daghfous, A., Ayadi, M., 2008. A report of 15 cases of small-bowel obstruction secondary to phytobezoars: predisposing factors and diagnostic difficulties. Gastro. Clin. Biol. 32, 596-600.

Cifuentes Tebar, J., Robles Campos, R., Parrilla Paricio, P., Lujan Mompean, J.A., Escamilla, C., Liron Ruiz, R., Pellicer Franco, E.M. 1992. Gastric surgery and bezoars. Dig. Dis. Sci. 37,1694-1696.

Dugan, F.A., Lilly, J.O., McCaffery, T.D. Jr. 1972. Dissolution of a phytobezoar with short-term medical management. South Med. J. 65, 313316. 
Dwivedi, A.J., Chahin, F., Agrawal, S., Patel, J., Khalid, M., Lakra, Y. 2001. Gastric phytobezoar: treatment using meat tenderizer. Dig. Dis. Sci. 46,1013-1015.

Erzurumlu, K., Malazgirt, Z., Bektas, A., Dervisoğlu, A., Polat, C., Şenyürek, G., Yetim, I., Özkan, K. 2005. Gastrointestinal bezoars: a retrospective analysis of 34 cases. World J. Gastroenterol. 11,1813-817.

Feffer, J.L., Norton, R.A. 1976. Letter: Dissolution of phytobezoar using pineapple juice. JAMA. 236, 1578.

Gaya, J., Barranco, L., Llompart, A., Reyes, J., Obrador, A. 2002. Persimmon bezoars: A successful combined therapy. Gastrointestinal Endoscopy $55,581-583$

Ha, S.S., Lee, H.S., Jung, M.K., Jeon, S.W., Cho, C.M., Kim, S.K., Choi, Y.H. 2007. Acute intestinal obstruction caused by a persimmon phytobezoar after dissolution therapy with Coca- Cola. Korean J. Intern. Med. 22, 300-303.

Heinz-Erian, P., Klein-Franke, A., Gassner, I., Kropshofer, G., Salvador, C., Meister, B., Müller, T., Scholl-Buergi, S. 2010. Disintegration of large gastric lactobezoars by N-acetylcysteine. J. Pediatr. Gastroenterol. Nutr. 50,108-110.

Ladas, S.D., Triantafyllou, K., Tzathas, C., Tassios, P., Rokkas, T., Raptis, S.A. 2002. Gastric phytobezoars may be treated by nasogastric CocaCola lavage. Eur. J. Gastroenterol. Hepatol. 14, 801-803.

Latic, F., Zerem, E. 2010. Phytobezoar of the stomach - laparoscopic approach. Dig. Surg. 27, 338.

Meseguer Ruiz, V.A., Calvo Hernan, F. 2008. Phytobezoar treatment with Coca-Cola. Med. Clin. 131, 479. Meyer, G.W., Clark, R.D., Brotman, M. 1973. Gastric phytobezoar and hypoglycemia.Medical management. Calif Med. 118, 66.

Nomura, H., Kitamura, T., Takahashi, Y., Mai, M. 1997. Small-bowel obstruction during enzymatic treatment of gastric bezoar. Endoscopy. 29, 424-426.

Robles, R., Parrilla, P., Escamilla, C., Lujan, J. A.,Torralba, J.A., Liron, R., Moreno, A. 1994. Gastrointestinal bezoars. Br. J. Surg. 81,1000-1 0 01.

Rumley, T.O., Hocking, M.P., King, C.E. 1983. Small bowel obstruction secondary to enzymatic digestion of a gastric bezoar. Gastroenterology. $84,627-629$.

Sanei Taheri, M., Kharrazi, S.M., Haghighatkhah, H.R., Moharamzad, Y. 2008. Unusual acute formed gastric bezoars due to plaster ingestion successfully treated by gastric irrigation: report of two cases. Emerg. Radiol. 15, 357-359.

Stanten, A., Peters, H.E. 1975. Enzymatic dissolution of phytobezoars. Am. J. Surg. 130, 259-261.

Türkmenoğlu, Ö., Dă̆, A., Çolak, T., Öcal, K.,Canbaz, H., Aydın, S. 2008. Akut intestinal obstrüksiyonun nadir bir nedeni: Bezoar Kolon ve Rektum Hastalıkları Derg. 18, 84-89.

Walker-Renard, P. 1993. Update on the medicinal management of phytobezoars. Am. J. Gastroenterol. 88, 1663-1666.

Wyatt, J.P., Haddock, G., Aitken, R.J. 1993. Gastric phytobezoar: unusual association and resolution. Postgrad Med. J. 69, 659-660.

Zissin, R., Osadchy, A., Gutman, V., et al. 2004. CT findings in patients with small bowel obstruction due to phytobezoar. Emerg. Radiol. 10, 197-200. 